REVISTA ANDALUZA DE ANTROPOLOGÍA.

NÚMERO 8: TURISMO DE BASE LOCAL EN LA GLOBALIZACIÓN

MARZO DE 2015

ISSN 2174-6796

[pp. 160-165]

http://dx.doi.org/10.12795/RAA.2015.i08.11

\title{
SIMÕES, DULCE (2013) FRONTERA Y GUERRA CIVIL DE ESPAÑA. DOMINACIÓN, RESISTENCIA】 usos de la memoria. Badajoz: Diputación Provincial de Badajoz. 399 pp.
}

\section{Pura Sánchez}

La obra "Frontera y Guerra Civil Española”, editada por la Diputación de Badajoz, recoge un amplio y profundo trabajo de investigación, llevado a cabo por Dulce Simöes en un periodo de unos diez años.

Dulce Simõeses antropóloga, especialista en poder, resistencia y movimientos sociales. Ejerce su labor docente en la Facultad de Ciencias Sociales y Humanas de la Universidade Nova de Lisboa. Fundadora del grupo GESSA y colaboradora en varias instituciones y proyectos investigadores multidisciplinares de ámbito internacional, su trabajo se organiza en torno a varios centros de interés: usos de la cultura y la memoria, políticas de identidad, relaciones fronterizas y políticas culturales. La obra incluye un prólogo del historiador Francisco Espinosa, quien realiza interesantes aportaciones, como el mayor y más cualificado investigador de la historia de ese territorio fronterizo desde el lado extremeño de la raya.

Las fuentes utilizadas son una mezcla fértil de documentación oral y escrita. Simões ha rastreado archivos particulares, diccionarios, enciclopedias y bases de datos, hemerotecas, archivos nacionales portugueses y españoles, así como archivos regionales y municipales de los territorios fronterizos.

Respecto a la documentación oral, la autora ha recogido y utilizado los testimonios de un numeroso grupo de informantes asentados principalmente en Barrancos, Encinasola 
y Oliva de la Frontera, tres localidades que configuran un territorio situado entre Huelva, Badajoz y el Alentejo portugués, un ámbito tornado conflictivo en el desarrollo tanto de la Guerra Civil española como de la posguerra.

Este trabajo de investigación, tanto metodológica como conceptualmente, es un claro exponente de cómo abordar la construcción de una "historia vivida", concepto desarrollado por el profesor Aróstegui para referirse a un presente histórico enmarcado en un "modo historiográfico" denominado "historia del tiempo presente". Pero la historia vivida debe hacer frente a no pocos problemas, que, a juzgar por el resultado de la investigación, la autora ha ido resolviendo de manera eficaz. Uno de ellos tiene que ver con el necesario proceso de documentación de experiencias de sujetos que están produciéndose todavía. Otro problema es, a decir del profesor Aróstegui, el de la calidad y cantidad de las informaciones disponibles. Para resolver estos problemas, la autora realiza una consulta exhaustiva de archivos y hemerotecas, como hemos indicado, tratando de contextualizar las experiencias narradas por los testigos, de modo que estas se incardinen en el relato obtenido de dicha documentación. Respecto a la segunda cuestión, la cantidad y calidad de textos manejados solo se alcanza con un proceso investigador sereno y dilatado en el tiempo, con una investigación cocinada a fuego lento, en la que se busca, se compara, se selecciona, se desecha material y se elige el más relevante. Ello explica de sobra el tiempo dedicado a este trabajo.

También la investigación muestra de forma práctica un camino, un método para construir esa historia vivida. Los caminos, ya lo decía el poeta, se construyen a medida que se transitan y eso ha hecho la autora, construir el camino a medida que analizaba y exploraba su propio objeto de estudio, que no es otro que la frontera.

Estudiar o historiar la frontera, en la historia del tiempo presente significa, en tanto que análisis de "procesos en curso", analizar procesos que tienen vigencia en el momento actual.

La frontera, la raya como se la denomina en esa zona, no es más que una demarcación prescindible en tiempos de paz, que se convierte en un espacio hostil y peligroso en tiempos de guerra y turbulencias políticas, de modo que los estados colindantes se apresuran a convertirla en un muro, mejor cuanto más infranqueable, en función de los intereses políticos y económicos de sus gobiernos, que intentan hacer aparecer como los intereses de la ciudadanía. En este sentido, resulta inevitable conectar lo narrado por Simões, en relación con la frontera portuguesa, con lo que viene ocurriendo en la considerada frontera sur de Europa, en Melilla particularmente, donde el muro es visible y criminal, aunque ese atentado flagrante contra los derechos humanos no logre sonrojar, siquiera sea levemente, a ningún gobierno de la "civilizada" Europa. 
Otro elemento que toma en consideración la autora para construir esta historia vivida es la referencia a los orígenes del proceso que se analiza, siendo consciente de que dicha referencia no significa en todo caso una explicación. Así, en el capítulo 3, se hace un retrato sociológico de Barrancos: el reparto desigual de la riqueza, el discurrir de la cotidianidad, marcada para los más por la supervivencia y la presencia inevitable de la miseria. A continuación, en el capítulo 4, se contextualiza la situación fronteriza y se analiza la presencia represiva del Estado Novo a través de la presencia en la frontera de la Guardia Fiscal y la policía política.

Ello contribuye de manera activa a analizar la lógica de la situación, estableciendo una relación causal entre las condiciones de vida de los habitantes de la frontera y la intencionalidad de sus actuaciones. Serán precisamente estas actuaciones las que, en esa coyuntura histórica conviertan la frontera, territorio compartido, en un territorio conflictivo y hostil o en un territorio refugio.

Como demuestra la investigación de Simões, estas actuaciones se inscriben en una dinámica contradictoria y complementaria: la represión y el control, que se ejerce desde el poder estatal, y que tiene como objeto el control no tanto del territorio, cuanto de las personas que lo habitan; pero también la resistencia, manifestada generalmente a través de redes informales de apoyo a los refugiados de una u otra adscripción ideológica.

La dinámica represión-resistencia cristalizará en actuaciones individuales, que tienen como motivación originaria el "miedo difuso" y la solidaridad respectivamente.

El miedo difuso es una reacción a una percepción subjetiva de peligro o amenaza generalizada, no por poco concreta irreal, que tenía consecuencias sobre las vidas y las costumbres de los habitantes de la frontera. Es obvia la relación entre miedo difuso y violencia, conformada esta por un conjunto de actuaciones, dirigidas por las fuerzas gubernamentales lusas o rebeldes españolas, aliadas para controlar a los habitantes del territorio fronterizo, que se materializaban en la represión del contrabando y en las acciones de control de la policía política. Este cuerpo represivo, organizado por Salazar, debía controlar a los exiliados portugueses que buscaban refugio en España, huyendo de la dictadura salazarista. Esta policía debió apoyarse también en las autoridades civiles y militares para ser efectiva y se configurará de forma más precisa, para actuar en la frontera, a partir de la guerra de España, cuando las autoridades municipales, la de Barrancos lo hizo, piden refuerzos militares para controlar la preocupante situación fronteriza, dado el considerable aumento del flujo de personas y las características de las mismas. Es en ese momento cuando la actividad fundamental de dicho cuerpo policial pasa a ser el control de extranjeros. Este control se ejercía en no pocas ocasiones en forma de "batidas" contra los fugitivos, que dejaban los campos sembrados de cadáveres, a los que los habitantes de los municipios fronterizos daban sepultura en un gesto de humanidad, 
sabiendo además que contar lo visto u oído podía costarles la vida. Las consecuencias fueron inmediatas: el terror se instaló en la población civil y las actuaciones de la policía política sirvieron para reforzar el sistema local de dominación. Este miedo difuso, en definitiva, en palabras de Hannah Arendt, que cita Simões, era el responsable de crear el súbdito ideal de cualquier gobierno totalitario: el que no distingue entre la realidad y la experiencia, entre lo verdadero y lo falso.

El miedo difuso produce silencio defensivo, silencio cómplice y colaboración más o menos espontánea. Y todo ello convivía con la solidaridad. Simões analiza en el capítulo 5, el fenómeno de los refugiados y la dinámica delación-ocultación. El caso de los refugiados españoles es un tema inexistente, a decir de la autora, en la historiografía portuguesa. Sin embargo, los testimonios recogidos en este libro dan cuenta de la existencia de esta solidaridad de origen diverso: desde la ejercida por el alcalde de Barrancos, de origen humanitario, que acogía en su casa a mujeres y niños, sin mirar filiación política, hasta la solidaridad con los vecinos, con los que se tenían relaciones familiares, comerciales o de amistad. El flujo de refugiados de ideología derechista, que se produjo al inicio del golpe y por el desarrollo de los acontecimientos en Extremadura, fue aceptado y consentido. Por razones obvias, no pasó lo mismo con los refugiados "rojos". La detención y entrega de españoles muy conocidos, que finalmente fueron asesinados en Badajoz -se reitera en la narración del caso del "tío Saturnino"- frenó dicho flujo y los hombres y mujeres que cruzaban la raya quedaban las más de las veces vagando por los campos, sumidos en la miseria y la desesperación y siendo amparados de forma ocasional y discreta.

Además, por estos mecanismos de control, la frontera perdió su permeabilidad: se habilitaron pasos fronterizos y las personas que tuvieran intención de cruzar debían llevar pasaporte. Definitivamente, la frontera se convirtió entonces, y todavía durante la posguerra, en un muro que se pretendía infranqueable, a pesar de las protestas de algunos alcaldes, por las consecuencias negativas que ello llevaba consigo.

Es interesante constatar, por lo dicho con relación a los refugiados, cómo la frontera actúa como un espejo, de modo que a uno y otro lado se reproduce la misma jerarquía social y las mismas divisiones de clase. Así, quienes en algún momento atraviesen la frontera, pensando en poner a salvo sus vidas -y también su estatus, en el caso de los refugiados derechistas-, serán acogidos por gentes de su mismo grupo o clase social, que los atenderán también según sus posibilidades económicas.

Y desde luego, las prácticas represivas son las mismas a uno y otro lado de la frontera, dado que las fuerzas del orden tenían una estrecha colaboración. Así lo demuestra la sencilla e impresionante narración de María dos Remedios Ramos, que da cuenta de cómo las autoridades portuguesas en colaboración con los falangistas españoles, desnudaron a un grupo de chicas, que habían bordado una bandera republicana, las raparon, les dieron purgante y las pasearon "como dios las trajo al mundo". Ella y otros vecinos tuvieron 
durante meses escondidas en sus pajares a algunas mujeres huidas, "porque nosotros también éramos pobres, no podíamos ayudar más de lo que ayudábamos”.

Otro aspecto importante es el lugar epistemológico desde el que se aborda este trabajo de investigación. La autora lo explicita en el primer capítulo, donde hace referencia al “diálogo interdisciplinar" entre la historia y la antropología. Más allá y por encima de las diatribas que históricamente hayan podido mantener historiadores y antropólogos, empeñados en definir y levantar fronteras más o menos nítidas entre historia y antropología, la autora se muestra convencida, y lo demuestra en la práctica, de que una y otra deben y pueden ir de la mano, porque se entienden como dos "modalidades de conocimiento interrelacionadas, aunque tienen presuposiciones mutuas sobre las realidades sociales que estudian, existiendo disposiciones convergentes, pero también articulaciones divergentes en el diálogo de las dos ciencias con la temporalidad".

En cuanto a la relación entre memoria e historia, la autora cree conveniente referirse también a esta cuestión en el capítulo inicial, afirmando que ambas no se confunden, sino que la historia empieza donde la memoria de los grupos sociales termina. Memoria e historia no son, efectivamente términos equivalente, pero las memorias colectivas deben ser consideradas materiales para la construcción de la historia. Precisamente Simões utiliza la memoria como el proyecto de futuro de los grupos excluidos de la historia, impugnando así "los modelos autoritarios y unidireccionales de interpretación social". De este modo, las memorias colectivas se convierten para los grupos sociales que las sustentan en un "capital simbólico" capaz de generar identidad y de facilitar la comprensión de la historia propia.

En este contexto de la historia vivida, la oralidad tiene una gran importancia, no solo en cuanto a las fuentes, a lo que ya hemos hecho referencia, sino también en tanto que transcriptora de lenguajes. El lenguaje en general y los lenguajes en particular dan cuenta, al menos en parte, de la conciencia y el pensamiento de los sujetos. Constituyen un modo de manifestación de lo humano, de lo histórico, por tanto. De ahí la importancia de las narrativas orales, en las que los testimonios están transcritos con el lenguaje de sus autores. De este modo, vemos cómo Simões acaba por nombrar actuaciones, actitudes o valoraciones con las expresiones utilizadas por los testigos: "Eran dueños de la tierra, del pueblo, de todo", "En aquella época no había reivindicación, había miseria...", "No éramos contrabandistas, trabajábamos en el contrabando", son expresiones de las personas entrevistadas que la autora utiliza para nombrar algunos subapartados de su trabajo.

Desde luego, los documentos orales adquieren en este contexto especial relevancia, dado que son los sujetos protagonistas de la historia los que narran en primera persona, del singular o del plural, tejiendo las memorias colectivas. La historia vivida así construida acaba con la jerarquía de los discursos y las narrativas históricas, así como con las voces 
autorizadas, en una palabra, con palabras de Guha, con el relato histórico en tercera persona y en pretérito perfecto.

Historiar la guerra civil, dando cuenta de su complejidad en el territorio concreto en que se sitúa la autora, aporta un importante saber sobre el acontecimiento que se aborda, además de un interesante saber metodológico, que ilustra a historiadores y antropólogos, aunque la intención de la autora no sea esa, sobre la conveniencia y relevancia del enfoque interdisciplinar y sobre cómo historiar el tiempo presente.

Elaborar una historia vivida de la frontera posibilita el acercamiento al estudio de otras fronteras, nunca idénticas, pero sí con elementos comunes y vigentes en el momento actual. Entonces, como ahora, en ese territorio común al que llamamos frontera, los gobiernos articulan dispositivos de control sobre las personas y el territorio, imponiendo unas reglas de uso del mismo que lo transforman en un muro que separa y excluye.

Así pues, este trabajo, que tiene como objeto de estudio la guerra civil española en la frontera entre Andalucía, Extremadura y el Alentejo, transita también por otros territorios fronterizos: el de la guerra civil, el de la antropología y la historia, el de la historia y la memoria. A fin de cuentas, la historia vivida hace posible ese tránsito.

Este trabajo de investigación, además de todo lo reseñado, tiene un valor añadido, como instrumento para una mejor comprensión de nuestro presente histórico, especialmente cuando desde los poderes estatales, y con vergonzantes políticas de inmigración, se pretende convertir a Andalucía en la frontera de diversos sures -el sur económico, étnico, religioso...- que contenga a legiones de seres humanos que huyen de una guerra sorda en la que, junto a las armas convencionales, se utilizan el hambre, la miseria, la explotación y la desesperación como armas de destrucción masiva.

Como muestra este estudio, siempre hay otro modo de habitar la frontera: no como guardianes, sino como habitantes libres de un territorio abierto. 